\title{
CREACIÓN NARRATIVA Y SOBRESEMANTICIDAD EN MARÍA, DE JORGE ISAACS
}

\author{
Enrique Marini Palmieri
}

Université de Valencianes et du Hainaut-Cambrésis

\section{PREÁMBULO NARRATOLóGICO}

\subsection{Relato, lector y caracterización}

Observando desde la materialidad exterior que es el libro, por intención del escritor, en una obra narrativa de ficción se le ofrece al lector un complejo entramado que va tejiendo la relación interna narradorpersonajes. Tal armadura constituye el nexo vital de la dinámica ficticia, es decir, lo intencional y tensorial. El autor establece dicha relación desde el presente de la escritura y construye una trama sintáctica, semántica y pragmática, que se articula merced al binomio enunciación-enunciado. En María, la producción de dicho binomio, al que podremos también denominar tópicamente relato-historia, se le confía 
a una voz exterior al binomio. Esta voz, supuestamente la del novelista, le ofrece al lector un texto que ella no forjó. De ahí que el estatuto del narrador posea una naturaleza equívoca, fluctuante, diríamos, que puede desorientar.

Según la Advertencia a los hermanos de Efraín que abre la novela colombiana, la enunciación se realiza en dos niveles. En el primero, se le informa al lector que hubo un primer destinatario del enunciado: Isaacs, cuyo estatuto esporádico concentra así una triple naturaleza: la de oyente y la de locutor, las que se resumen en la de autor-narratario, es decir, la de depositario del relato y de la historia. Estatuto intenso, precario y fugaz a la vez, que deja de existir en cuanto el lector se encuentra con el yo de Efraín en el primer capítulo de la novela.

Este primer nivel lleva al segundo, en el que el lector adquiere también un doble estatuto: por un lado, el suyo propio y, por el otro, el de «hermano» de Efraín, personaje ayudante en la historia. Resulta ser también doble su naturaleza de lector: la de carne de ficción del presente de la historia y la de entidad perteneciente a la realidad contingente del presente de la lectura. El lector es a la vez ese tú-Ustedvosotros-Ustedes y narratario al que se dirige el locutor en la interioridad del binomio relato-historia que constituye la materialidad de María.

Estos diferentes niveles en la función narrativa, aparentemente compleja, pertenecen, después de «Eureka», de Edgar Allan Poe, a una línea frecuente en las novelas románticas como Raphaël de Lamartine, Ernesto de Castelar, François le champi de George Sand, amén de la tan traqueteada en la estela analítica de María, la del episodio norte-americano indígena del Genio del cristianismo, la de Atala de Chateaubriand, por no citar más que algunas de las emblemáticas en la relación de la novela de Isaacs con su contexto creativo. A esta enumeración volveré en alguna otra oportunidad, para que se observe detenida y separadamente la interrelación entre todas ellas y María, y en particular la suya con Atala, relación sobredimensionada, a mi parecer.

Por el momento diré que, como los autores de estas novelas decimonónicas, Isaacs se descarga de su omnisciencia y de la propia experiencia vital que alimenta la imaginación de cualquier novelista, en un personaje central, en este caso en el masculino de Efraín, transformándolo en el narrador de la historia. A la vez, el lector se vuelve destinatario, dentro y fuera de la tensión relato-historia. Merced a la elec- 
ción de esta economía narrativa, la historia de Efraín y de María se nutre de un juego ambiguo que va de dentro de la realidad de ficción afuera de ella. El resultado es tópicamente romántico y la implicación del lector, total. En efecto, cuando se trata de narrar la historia de una pasión, los novelistas románticos recurren a este desplazamiento del centro de la función narrativa, ya que el punto de vista homodiegético, o intradiegético no puede ser lírico, ya que dicho enfoque abre a un enunciado que informa, discurre, reflexiona. El lirismo es especular, por antonomasia. Desplazando este juego de espejos de su centro, la novela romántica logra un mecanismo conativo del discurso y así implica por entero al lector.

La naturaleza narrativa de María se sitúa, pues, entre historia de ficción e historia verídica, siendo esta equivocidad el umbral que abre a un mecanismo semántico fundado en la analogía, o en la homología, como diría Barthes, no tanto en la veracidad y la ficción de las situaciones como en la construcción sobresemantizada de los personajes; en particular, de Efraín y María. La sobresemanticidad acerca el mundo de ficción al mundo real - que no forzosamente autobiográfico, dimensión ésta cuyo alcance se limita por supuesto, a los lectores avisados que conocen los pormenores de la vida de Jorge Isaacs - al mundo de ficción. Dado este mecanismo que implica al lector, en virtud del cual ya no es necesario construir de manera forzada la enunciación para producir un enunciado factible, en realidad, excluiría la dimensión autobiográfica de la lectura ingenua de María.

En un brevísimo paréntesis resumido, diré que llamo lector ingenuo a aquel que lee por el placer de leer, sin preconcebidos narratológicos, sin otra meta que la de asumir el papel de lector al que el escritor destina en primer lugar su obra. El lector avisado es aquel que lee en posesión de los conocimientos necesarios como para entrar en la weltanschauung del autor, lee a sabiendas, lee en el filo de la navaja de lo interpretativo. La lectura avisada posee diferentes niveles, según su meta. Una, propia de las actividades universitarias, es la consensual, destinada a cumplir con el contrato entre el profesor y el estudiante. De éste nace la presente reflexión.

Entonces, y puesto que la frontera entre realidad y ficción se ha desvanecido, todo el trabajo de justificación, de persuasión, de adecuación de los personajes a la economía de la historia, se simplifica y la construcción de éstos por sinécdoque, por contexto y por referentes, se halla facilitada. Sin embargo, y propiamente respecto al personaje de 
María, su identificación con una realidad tradicional, digámoslo así por el momento, resulta asequible a los lectores ingenuos. Éstos, «hermanos de Efraín», narratarios de la historia, merced a la sobresemanticidad, realizan a partir del nombre de la muchacha el necesario proceso de apropiación del personaje en la concreción del acto de leer. La carga referencial no sólo es contextual, histórica, religiosa, sino también afectiva, universal diría yo. Por el nombre, María, referente virginal, significante de la identidad de un ser que existió, la heroína de Isaacs, vive como vivió María la Virgen, con todos sus atributos existenciales. Identificación que irá realizándose tanto en el relato como en la lectura, jugando con los recursos narratológicos propios de la novelística romántica, es decir, sintaxis diacrónica y sincrónica de la prosopografía de María por sinécdoque (atuendo, cabellera, lecturas) y por etopeya (sentimientos de su naturaleza profunda y de los de su relación con el mundo que la rodea). En su dimensión literaria, este retrato constituye un verdadero arquetipo decimonónico. Dice Henry James en Art of fiction (1988): "What is character but the determination of incident? What incident but the illustration of character?» (apud: Martin, 1986: 116).

Tal riqueza de recursos narrativos nos lleva a que nos adentremos en el natural de esta María de ficción. Por la compleja trama crea-tiva, no podemos dejar de pensar en que se trata de una figura de carácter sobresemantizado, como si fuera uno de esos personajes de $\grave{A} l a$ recherche du temps perdu de Proust, que Roland Barthes analizó. En efecto, la sobresemanticidad, o la sobresignificación, es un concepto que figura en Proust et les noms, ensayo breve en el que Roland Barthes observa cómo los nombres de En busca del tiempo perdido se vuelven independientes de la sintaxis en la que se hallan incluidos: «Lo que se cuenta respecto de un nombre cumple un proceso metonímico que liga entre ellas a unidades de sentido plenas», afirma el ensayista. Así, como los personajes revisten una naturaleza poética que los vuelve verdaderas figuras que son, éstos encarnan a la vez imágenes y puros significados «ofrecidos como los de una lengua denotativa a todo un sistema de sentido». Este mecanismo descubre una afinidad natural entre el significado y el significante, y, aunque aquí se trate de nombres propios, añade Barthes (1967), se realiza lo que afirma Cratilo: «La propiedad del nombre consiste en representar la cosa tal cual es».

Creo que, y esto es lo que intentaré analizar, la sobresemanticidad plasma en la historia de María color e intensidad y le otorga a la heroí- 
na el protagonismo absoluto que anuncia el título. Esta elaboración metonímica de la persona de María se liga a la intencionalidad del autor, crea tal profundidad que ésta abre a una dimensión cuya esencia justifica la historia toda. Dimensión profunda de la carne paradigmática de un personaje que llega al corazón de los «hermanos de Efraín», genérico que habrá de aceptarse no sólo como masculino sino también como femenino. La muchacha es sentido, causa y efecto, objeto y objetivo.

Los receptores del momento en que salió la novela acogen desde el horizonte de espera que les es propio en la red de ideas que son las suyas. Sin embargo, los receptores posteriores, que en principio pertenecen a otro horizonte de espera, la acogerán igualmente, por los mismos motivos, puesto que éstos se proyectan en la eternidad de la esencia y del símbolo con los que se nutre el personaje desde su referente. Porque, si la realidad de María se mide en función de las convenciones ideológicas decimonónicas, su carácter sobresemantizado aleja al personaje de dichas convenciones diacrónicas y le confiere una extraña eternidad. Esto es así dado que la imaginación analógica y simbólica propia de la tradición judeocristiana constituye la columna vertebral de la creación narrativa de Isaacs. Sobresemantizada, María , por ejemplo, comunica, a esos padre y madre innominados en la novela, su dimensión paradigmática. Lo mismo ocurre con Efraín. Incluso con la enfermedad fatal que sufre la heroína, epilepsia que adquiere dimensión apocalíptica, en el sentido literal, de la historia, o aun quizá epifánica, ya que el mecanismo de la identificación del lector se concreta no sólo con María sino también con Efraín. El desplazamiento del centro de la función narrativa y la sobresemanticidad hacen de María una gran novela de amor, y las resonancias de la obra de Isaacs salen ganando en matices y objetivos.

\subsection{Referentes compartibles}

A mi parecer, Biblia, Antiguo Testamento y Nuevo Testamento constituyen la base de la sobresemanticidad que construye a la pareja central de la historia en María. Jorge Isaacs, hijo de un judío converso y de católica, debía de conocer la tradición tipológica judeocristiana, y ello como judío más aún que como católico, dado que entonces la jerarquía de la Iglesia preferentemente reservaba la lectura y exégesis de los textos 
bíblicos a los ministros del culto romano, en particular durante la Santa Misa. La lectura avisada de María pone de relieve la existencia de dichos referentes universalmente compartibles que componen la proyección profética y universal que Isaacs quiso darle a su novela. Los lectores ingenuos recibieron dicha proyección no, obviamente, de manera analítica sino estética, intuitiva, según el horizonte de espera de la época y en relación concreta con esa realidad del momento que imponía un discurso sintético, armonioso y utópico incluso a las obras de ficción. A través de los nombres de la heroína, María y del héroe-ayudante y narrador homo y heterodiegético a la vez, Efraín, Isaacs deletrea sus intenciones acordes con el entramado idológico, que era el suyo entonces.

Haré un brevísimo repaso tipológico de la pareja en María, empezando por la figura de Efraín.

En el Antiguo Testamento, José había sido el preferido de Jacob entre sus hijos, por ser el primero que tuvo con Raquel, por ser hijo del amor y «el hijo de la vejez». Sus hermanos mayores lo despojaron de sus vestiduras y lo vendieron a los egipcios. Por el don que poseía de penetración simbólica de la realidad, y por su visión analógica de los designios misteriosos de Dios, a los que se añade el de su profunda religiosidad, la tradición de los Padres de la Iglesia primitiva (Melitón, Justino, Tertuliano, Hipólito) consideran que José prefigura a Cristo crucificado (cf. Martine Dulaey, 1989).

José tuvo con la egipcia Aseneta dos hijos: Manasé y Efraín, siendo Manasé el mayor. Efraín nació (Génesis, 46, 50) durante los siete años de fertilidad que precedieron a los de hambre en Egipto (Génesis, 41, 25-36); razón por la que José eligió para nombrarlo y celebrar aquel suceso feliz la raíz hebrea fârâh (fructificar, ser fecundo) y así decir hifranî, «Dios me ha dado frutos en esta mi tierra de aflicción» (Génesis, XLI, 52). Más tarde, y respondiendo al llamado de Jacob, viejo y ciego, José le presentó a sus dos hijos para que los bendijera. Para facilitar la bendición, puso a la derecha del patriarca al mayor, Manasé. Sin embargo, el abuelo, que prefería al menor, tendiendo tradicionalmente la mano derecha, fue y bendijo al niño que estaba a su izquierda, es decir, a Efraín (Génesis, 47, 13, 14, 17, 19-20). Así, éste no sólo es «el fecundo», sino también el elegido. Jacob predijo que tendría «gran entereza moral y fuerza de carácter» (Génesis, 49, 23-24). Moisés lo compara con un toro, y el Salmo 49 (hebreo, 50) dice que Dios lo llama «fuerza de Su cabeza». La tribu de Efraín, núcleo del futuro reino de Israel, ocupó las tierras fértiles que Dios le indicó, protegidas por montañas, cuyo centro geográfico era la montaña llamada de Efraín, 
montaña que Salomón eligió como primer distrito del reino reunido de Israel (Primer Libro de los Reyes, 4, 8; Libro de Isaías, 7, 17). Los centros religiosos en esta región fueron los de Silo y Sichem.

María es primero Ester, antes que se la bautizara con este nombre a pedido de su padre. Con Ester nos situamos en la línea de Raquel y Jacob, ya que la reina hebrea de Persia pertenecía a la tribu de Benjamín, hermano menor de José. Al inicio de la novela nos hallamos en la misma perspectiva genealógica. Sin embargo, la niña Ester es hija de Sara y de Salomón, primos del padre de Efraín. Esta precisión genealógica, curiosamente puntualizada, sorprende si se tiene en cuenta que no se declinan los nombres de pila de los padres de la familia de Efraín. Y, para el lector avisado, precisión e imprecisión narrativas actúan como un llamado para que se detenga en considerar en detalle la genealogía de la niña. En efecto, se observa que se da en ésta el cruce entre dos ramas que en un momento de la historia hebrea se enfrentaron ${ }^{1}$ : Sara se sitúa en la vertiente de las doce tribus de Israel que no rompió su Alianza con Dios. Salomón no, ya que pertenece a la tribu de Judá; aunque en la suya se hallará la casa de David, a la que pertenece la Virgen María, por su matrimonio con José. Cuando la Ester de la novela pasa a ser María por el bautismo, su referente pasa de la tribu de Benjamín, de la casa de Jacob, a la casa de David, la de la Virgen María, la del Mesías, la del Nuevo Testamento, la de la Nueva Alianza, la de la Salvación y del futuro religioso de la Humanidad. Todo parece estar sugiriendo que María posee una predisposición a configurar no sólo la continuidad entre el Antiguo y el Nuevo Testamento, sino también la unión armónica de opuestos, la reunión armónica que luego supondrá el amor de Efraín por ella. Efraín, cuyo referente bíblico es el de la casa de Jacob, al enamorarse de María, realiza otra vez el cruce entre las dos vertientes familiares de la historia del pueblo hebreo, pero esta vez en el sentido inverso al que se realizara entre los Salomón y Sara de la novela.

Se riza el rizo entre el Antiguo y el Nuevo Testamento, entre la Alianza de Moisés y la de Cristo, y, conforme a lo que encara el espí-

${ }^{1}$ El árbol genealógico que parece inspirar a Isaacs èn su novela es el siguiente: Abraham tuvo con Sara, su esposa legítima, a Isaacs; éste con Rebeca tuvo a JacobIsrael, quien con Raquel tuvo a Benjamín y a José; y éste, en Egipto, a Manasé y Efraín. Sin embargo, antes de que Sara pariera en su vejez a Jacob, por voluntad de Dios, Abraham tuvo con su criada Agar a Ismael, de quien nace Jesé, padre de David; éste, a su vez padre, de Salomón, siendo todos de la rama de Judá. El profeta Isaías en su Libro $(7,8-9 ; 9,7-20 ; 11,12-13)$ cuenta el cisma que se produjo entre la casa de Judá, a la que pertenecen, pues, David, Salomón y José con la Virgen María; y la de Jacob y las doce tribus de Israel, a la que pertenecen Sara, José, Ester y Efraín. 
ritu sintético decimonónico, en la proyección icónica de la pareja central de María, se lee el mensaje, según el cual el futuro de la Humanidad puede emprender un camino hacia una nueva era de armonía, si la alientan las fuerzas religiosas tradicionales que imprimen la unidad moral y social tan ansiada en el siglo XIX. En este sentido, se lee en el libro del profeta Zacarías (10, 6-7), donde refiriéndose a Efraín, el Elegido y el Fecundo, y a Judá con María, y habiendo hecho de ésta el arco y de Efraín la flecha (el simbolismo universal es evidente: el principio femenino de la figura del arco, el masculino en el de la flecha, fecundados por el Amor de Dios): «Fortificaré la Casa de Judá y salvaré la Casa de José; las restableceré en su poderío, puesto que me apiadaré de ellas como si yo no las hubiera rechazado».

Es más, en el libro del profeta Oseas (5 a 14, y en particular los capítulos 5, 3-4 y 6, 4-6) Dios dice: «¿Qué te haré, Efraín? ¿Qué te haré, Judá? Vuestro amor es como una nube matutina en la aurora, como el rocío que se evapora». Pero, a causa de las disputas (entre el pueblo de Jacob y el de Judá, entre las ramas opuestas; son éstas: la de la unión del reino de Israel y la del Mesías) que Dios les reprocha, Él añade: «No te destruiré una vez más, Efraín [...] Puesto que lo que quiero es amor, que no sacrificios; el conocer a Dios, que no holocaustos». Es decir, quiere días mejores, días de paz entre los hombres entregados al Amor de Dios, a Su justicia, a Su sabiduría; ni días sin celos, ni muertes, ni perversiones, ni atrocidades, «ni desórdenes religiosos ni sociales» (Oseas, $)^{2}$.

Para el lector ingenuo, Ester-María es el modelo de absolutas purezas, belleza y entrega a las significaciones de Dios. Y Efraín, un dechado de bondad y resignación ${ }^{3}$, como su figura bíblica, la que está recordando la renovación de la Alianza que hubo sellado Dios con

${ }^{2}$ El libro más importante para el alcance de la figura de Efraín, donde se confunden el hijo de José y su descendencia; figura de la que no doy, obviamente, todos los detalles relativos a su tribu, ni de las guerras contra la casa de David, contra Judá.

3 No se debe de olvidar el carácter humano de Efraín - ni tampoco, que sea dicho de paso, el de María-. Sus emociones amorosas, su cuidado por todo lo familiar, su interés generoso en lo social, su ternura por el paisaje patrio, sus costumbres y sus gentes sitúan a los jóvenes muy cerca del lector ingenuo. Una muestra de la humanidad de Efraín podrían constituir el placer sencillo y sensual a la vez en los baños que toma, solo o en compañía de amigos, en el campo, a lo largo del hilo narrativo en diferentes circunstancias. Baños en aguas claras de ríos, arroyos, remansos y estanques del Valle del Cauca, en medio de naranjos, de flores, de perfumes agrestes y de las flores que pone en el agua (capítulo $4 .^{\circ}$ ); baños compartidos con amigos (capítulo $9 .^{\circ}$ ), o con Salomé (capítulo $49 .^{\circ}$ ), en medio de garzas y chicharras y sardinas plateadas (capítulo $19 .^{\circ}$ ), baños que a veces se califican de «oriental» (capítulo $4 .^{\circ}$ ) o de un «orientalismo salvaje» (calificativo oximórico del capítulo 57. ${ }^{\circ}$ ). Vid. Vich-Campos (1984). 
Moisés (Éxodo, 24) y que se concreta luego con las doce tribus de Israel, teniendo en cuenta la bondad de Efraín, hijo de José (Jeremías, 31, 1-9). El amor que se abrigan mutuamente María y Efraín, ¿sería, pues, la propuesta metafórica y profética de una alianza por un mundo de orden social y por su armonía moral en un marco de religiosidad judeocristiana? En dicho caso, podríamos pensar que la ideología en la novela es socialista mística. Quizá ello podría verse corroborado emprendiendo un estudio de la relación entre un libro sobre el tema, que figura en el Fondo «Isaacs» de la Biblioteca de Bogotá, Análisis del socialismo y exposición clara, metódica e imparcial de los principales socialistas antiguos y modernos y con especialidad los de SanSimon, Fourier, Owen, P. Leroux y Proudhon (Bogotá: Librería de S. Simonot, 1852) y María.

\section{MARÍA, HEROÍNA DE NOVELA}

\subsection{Introducción}

No voy a pasar revista a las propuestas que los críticos han ido formulando relativas al aspecto autobiográfico de la novela de Isaacs -Efraín sería Jorge Isaacs, por ejemplo-, porque no creo que los lectores ingenuos del XIX basasen en este detalle su pasión por la historia de María. Además, porque el presente análisis parte de la lectura ingenua, para luego ampliarse, evidentemente, pero teniendo siempre presente que la elaboración de los personajes apunta en primer lugar a los lectores ingenuos. Tampoco creo que un escritor se fije tan pocas miras como para quedarse con la de plasmar privilegiadamente la historia de su vida por el solo hecho de plasmarla, sin desear proyectarla en una dimensión de ficción que descubra lo universal que pudiese existir en su propia experiencia. Siendo obvio que un libro de memorias no excluye ni la reflexión ni la proyección semántica de personajes y hechos pintados.

Para una lectura avisada, este aspecto es más que secundario, a mi parecer. Sentido éste que se halla matizado por el diálogo respecto de las implicaciones autobiográficas del personaje de la heroína que tuvieron Baldomero Sanín Cano y E.M.S. Danero (cf. edición en Santa Fe (Argentina): Castellví S.A., 1966, p. 10 y 11; 
también figura la disertación del ensayista colombiano en la Sociedad de Conferencias en Buenos Aires). El ensayista colombiano, después de afirmar: «He conocido a la interesante mujer, esa mujer de quien se dijo, y se continúa diciendo que sirvió de modelo para el retrato espiritual de María [...]. Por su abolengo estaba ligada con aquellos O'Donnel irlandeses que tanto han figurado en España. Tenía el cabello, los ojos, el color de la piel característicos del celta que pobló Irlanda. El novelista la hace morir joven, de extraña enfermedad». Sin embargo, Sanín Cano añade que, cuando se tocaba el tema de quién sirvió de modelo para su personaje de ficción, Isaacs mostraba «mal humor» y le daba entonces a la conversación «otros sesgos».

La cuestión queda zanjada, quizá, en la novela misma, cuando, en el capítulo 45, piensa Efraín: «[...] María continuaba siendo para conmigo solamente lo que había sido hasta entonces: aquel casto misterio que había velado nuestro amor, lo velaba aún», ese "castísimo delirio» con el que el muchacho sueña, María ya muerta (cap. 64). Un «casto» misterio ligado a la tipología judeocristiana, como se verá al tratar el tema de la construcción del personaje de Ester-María ${ }^{4}$.

Por su lado, Francisco Monteverde (1944), en cuanto a la genealogía de la novela de Isaacs, afirma:

${ }^{4}$ El bíblico Libro de Ester cuenta la historia, en siglo V..$^{\circ}$ antes de Cristo, de la sobrina de Mardoqueo, de la raza de Benjamín, hijo de Jair. Muerto Abigail, el padre de la niña, así como la madre, Hadasa, el tío Mardoqueo recoge a Ester, quien vivía, pues, en Susa, Estado de Elam, en tiempos de Asuero, rey de Persia. Con otras jóvenes, Ester fue presentada al rey, quien la prefirió y se casó con ella, volviéndose así reina de Persia. Ignorando que su esposa era de raza judía, Asuero mandó que exterminaran a los judíos, impelido por las intrigas de su consejero Aman. Mardoqueo suplica a su sobrina para que intervenga ante el rey. Ester, después de haber ayunado durante tres días, aunque el rey no la había llamado a su lado, se presentó ante él y lo invitó a un festín, junto con Aman. Durante el banquete, Ester emprendió la tarea de explicarle al rey cuán injusta era la orden de exterminio y cuán responsable era Aman en ello. Asuero se dio por convencido ante los brillantes y veraces argumentos de Ester y suprimió la orden; es más, Aman fue colgado en lugar de Mardoqueo. Ester había salvado a los judíos con la ayuda de Dios.

El tema del personaje bíblico Ester figura en la literatura clásica a través del relato de Flavio Josefo (37-95), y, para muestra de la dimensión literaria del personaje, baste con citar, con total arbitrariedad,la Tragicomedia de la hermosa Ester, de Lope de Vega, y Esther, de Racine. Boleslao Lewin señala la importancia de esta figura entre los criptojudíos en América Hispánica y recuerda que algunas de las víctimas más tristemente célebres del Santo Oficio en México, Luis de Carvajal y sus hermanos, lo fueron por haber celebrado a Ester en la noche del Purim, fiesta religiosa y nacional por lo dicho antes. Purim, ('suerte' etimologicamente), es promesa de tiempos mejores, mesiánicos, visionarios. 


\begin{abstract}
Jorge Isaacs escribió María combinando recuerdos personales, añoranza y ensueños. "Es evidente, dice Javier Arango Ferrer, que Isaacs tomó de la realidad el paisaje y algunos personajes, pero María es una ficción novelesca [...] Efraín no fue en la vida real el poeta, sino su hermano y el muerto no fue María sino Efraín. María era una esclarecida joven bogotana llamada Mercedes. Jorge Isaacs idealizó, pues, el idilio que tronchó la muerte de su hermano.» Pero también hay que recordar el precedente del poeta colombiano José María Gruesso, que murió dos años antes de que muriera Jorge Isaacs. Fue un precursor del romanticismo y vivió la realidad lo que Efraín en la novela.
\end{abstract}

\title{
2.2. Prosopografía por sinécdoque
}

La voz que va construyendo el personaje de María es principalmente la de Efraín. Ésta fluctúa, como ya lo hemos visto, en su relación con la historia: es omnisciente (caps. 7,27 ) y a veces no (caps. 31,46 ), asume la función de narratario oyendo el relato retrospectivo de Estefana-Nay (cap. 43) y leyendo las cartas de María (caps. 54-56), liga las naturalezas homodiegética e intradiegética para describirse (caps. 10, 27) y describir a María (cap. 13) ${ }^{5}$. Obviamente, dichas fluctuaciones enriquecen las perspectivas etiológicas del retrato de la muchacha.

En el primer capítulo de la novela, el lector se entera de manera sinóptica de la genealogía de la niña que llega a Colombia con tres años, «a la sazón» (cap. 7) en compañía de su tío, padre de Efraín. El niño tiene aproximadamente siete años. Muchos críticos han insistido en determinar con exactitud la diferencia de edad entre los primos, poniendo de relieve lo que consideran contradicciones en la narración. Tengo entendido que Isaacs le resta importancia al detalle, indicando, sí, lo que hay que retener: que el niño es mayor que la niña.

A su llegada a Colombia, antes de su bautismo, María es una niña judía, nacida en Jamaica, dominio inglés desde que España la cedió a Inglaterra en 1670 por el Tratado de Madrid. Es algo que no se oculta. Así, por ejemplo, en el cap. 32 Efraín le dice: «-No hagas caso, judía-, así solía llamarla algunas veces cuando se chanceaba con

5 Es a mi parecer, el retrato más completo, más simbólico de todos: su casta sensualidad, dualismo oximórico decimonónico, marca la novela con el sello ejemplar del genio del cristianismo, a la vez que posee la eficacia narratológica de situar a los héroes el uno frente al otro: ella, poesía armoniosa vital y espiritual, él, voz fecunda en cuanto que se la ofrece a sus «hermanos» como ejemplo de perfección cristiana. Véase, también, el cap. 47). 
ella». Es inglesa y, obviamente, habla inglés. En el cap. 7 se lee que «[ella] Hablaba bien nuestro idioma», y sus cabellos eran «de color castaño claro», color que conserva hasta los nueve años. Poseía «la hermosura de las mujeres de su raza» (cap. 3); «su» raza se verá determinada por su atributo: «nuestra raza» cuando ya María se ha integrado toialmente al grupo social y familiar del Cauca, y que se tratará de describir con orgullo, su «seductivo recato de la virgen cristiana» (cap. 4). La equivocidad que va del «su» al «nuestra» es eminentemente sintética: raza judía, raza cristiana; raza colombiana (del Cauca), raza americana. María, cifra de la esperanza bíblica, lo es también de una perfección humana, moral, universal.

Cuando Efraín recuerda su vuelta a casa después de los años pasados en Bogotá estudiando (cap. 3), con el apasionamiento de quien ha amado y perdido lo amado, nos describe a su prima hermana: hermosa; de ojos brillantes; largas pestañas; labios rojos, húmedos y cariñosos, ligeramente imperativos; abundante cabellera castaña obscura como el carey sombreado, arreglada en dos trenzas y a veces suelta y larguísima, cuyo matiz pone de relieve la blancura mate de la piel. Manos cuidadas como las de una reina, aristocráticas, «hechas para oprimir frentes como las de Byron», y brazos deliciosamente torneados, «mujer tan seductora en medio de su inocencia», tan «bella como la creación de un poeta». Por lo general, la muchacha viste trajes de muselina blanca, azul o verde; lleva flores en los cabellos (claveles y rosas, y, por supuesto, las azucenas de las sierras que poseen un valor simbólico amoroso y virginal y sabio a la vez en la historia) ${ }^{6}$. A menudo lleva en los hombros, cubriendo el cuello y el escote, un pañolón de color rojo.

${ }^{6}$ Resulta evidente que Isaacs recuerda la tradición bíblica de las azucenas y de las rosas, flores de la virginidad espiritual y física, alegorías del amor puro del alma por su Creador. Este amor es el centro arquetípico de la perfección a la que tiende el espíritu en su aspecto fértil, receptivo a la fuerza creadora de lo divino. Las rosas y azucenas en María son símbolo de las virtudes virginales de la heroína, de su armonía interior, la cual se refleja en los demás personajes de la novela. Respecto del simbolismo de dichas flores, brevemente se ha de señalar que las cuentas del rosario son las rosas de la Virgen, quien como rosa mística es la figura del alma que, en su perfección se entrega confiada a Dios. A las azucenas las ve San Mateo como las alegorías del entregarse al Creador $(6,28)$. El lector recibe la carga sugerente de este simbolismo tradicional y la misma armonía lo gana. Suyo es, pues, el imperativo mensaje armónico del enunciado de Isaacs, y de aquél mana la nostalgia por un mundo de orden y de amor. Amor puro (cap. 4), árbol de la fidelidad amorosa (cap. 45 ), el rosal. Las rosas son también alegorías de la sensualidad, de la pasión, del «magnetismo» del ser humano en plena armonía espiritual y física (caps. 5, 6, 11). Las azucenas son las acompañantes naturales en este mundo alegórico del amor sublimado (caps.11, 24, 45, 56), que se concreta en la virginal y mariana aparición final de María en el sueño de Efraín. 
En el cap. 12, Efraín se detiene en uno de los detalles que le adelantan al lector la sobresemanticidad que, por metonimia, también construye el personaje de María, el de la «sonrisa castísima», hoyuelada. Sonrisa que, con fondo de luna que argentea el paisaje y de rosales que lo perfuman, encarna las razones que impelen a que el muchacho trate de «hacer un paraíso de la casa paterna». La misma sonrisa que él sorprendió en el rostro de la Virgen pintada por Rafael que cuelga en el oratorio de la casa (cap. 37): «se le parece tanto a María», piensa Efraín en un arrebato amoroso, cuando tendría que haber sido lo contrario: que María se le parece a la Virgen. La inducción hacia lo que será una elaboración sobresemantizada del personaje se concreta, pues, en este capítulo. Lo que se podría considerar un lapsus en los labios del muchacho da la prioridad a María y pasa a un segundo plano a la Virgen, indicando la equivocidad semántica de la comparación apasionada. Se sobreentiende lo contrario: María es la Virgen, puesto que Ella se parece a María. Esta equivocidad plasma en la heroína todos los atributos de la Virgen, y, por antonomasia, recibe la propia sobresemanticidad de la Madre de Dios, la Virgen. Ella es la heroína y todas las adolescentes virginales.

Su voz es la de una niña, dulce y grave a la vez (caps. 4,12 ); su acento es musical, mágico, a veces lento y profundo. Articula claramente las palabras (cap. 12), palabras cuyo contenido siempre se le hacen a Efraín como de otro idioma, a fuerza de pureza de sentimientos y de juicios. Escuchando la lectura que éste realiza y seguro que comenta a sus hermanas, del Genio del cristianismo, María muestra ser inteligente y memoriosa, amén de poseer gran intuición de las verdades bíblicas, intuición por la cual a menudo, «casi siempre con triunfo infantil», se adelantaba a las explicaciones de Efraín (cap. 12). María se muestra en estos casos sensible, cristiana, llena de fe: «su alma tomaba de la paleta que yo le ofrecía los más preciosos colores para hermosearlo todo». «El fuego poético» de Chateaubriand, añade, contribuía a divinizarla y a plasmar en ella encantos desconocidos (cap. 13). Tal actitud está conforme con el cariño, la ternura, la abnegación, la disponibilidad que demuestra María en su ámbito familiar y social. Dechado de perfección humanitaria, como dice el siglo XIX, merece de su hermano pequeño, Juan, y de las mujeres de la familia el apodo de Mimiya. María resume en sí «la más arrobadora expresión» llena de «la ternura y el pudor, la reconvención y las lágrimas». Su perfección es, pues, tanto humana como angelical, virginal. 
A la vuelta de Efraín a casa, María, ya hecha una joven, lleva el pelo arreglado en dos trenzas de color «castaño oscuro» (cap. 3). Detengámonos en este detalle prosopográfico unos instantes. Recogido o suelto, el pelo es un carácter suficientemente importante, puesto que Efraín, ya fallecida María, lo vislumbrará cayendo y ocultándole el rostro en la visión que tiene de su amada fallecida, desvanecida en el pasado como sus sueños de felicidad, en ese momento en que se apoya con los codos en la ventana del cuarto (cap. 62). El detalle merece que se lo observe en el sentido de un simbolismo tradicional de fácil reconocimiento.

El color, primero castaño claro (cap. 7), será luego de ese «castaño luciente» que ilumina la blancura de las pequeñas azucenas que lleva en la cabeza (cap. 10). Más tarde se compara la cabellera de María con el color del «carey» o del «carey sombreado» (cap. 12). En la descripción que hace Efraín de María junto a su padre enfermo se lee: «Las negras trenzas de María sombrearon aquella cabeza cana y venerable a que tan tiernamente ofrecía, ella, su seno por cojín» (cap. 36). Pero, en realidad, no es negro, sino oscuro, como se lee casi al final de la novela, en el cap. 50: «[...] traje verde que tan hermoso contraste formaba con el castaño oscuro de sus cabellos peinados en dos trenzas [...]». Cuando el ave negra aparece en el cap. 47, se lee: «Algo oscuro como la cabellera de María y veloz como el pensamiento cruzó por delante de nuestros ojos». Todo se organiza como si en el desarrollo de la vida de la muchacha, que se convierte al catolicismo, aprende español, crece y se adapta a su nueva realidad, para volverse una joven como las hermanas de Efraín; como si el color del pelo fuese apuntuando la transformación de una niña de Jamaica en una mujer del Valle del Cauca, de una inglesa en una colombiana. Pauta es, pues, este detalle capilar de la conversión total del personaje.

Otro aspecto de este detalle prosopográfico que abre a la dinámica etiológica, y de allí a lo simbólico femenino, es la disposición de la cabellera; por lo general, en trenzas, «como mis hermanas», dice Efraín, determinando el criollismo de María (caps. 3,16, 23, 35, 36, 50). Las trenzas le dejan el pelo a medio rizar cuando lo lleva suelto (cap. 46); o con bucles «rodándole sobre los hombros» (cap. 27). Tal disposición inspira el conocido retrato de que de la heroína hará, siguiendo las indicaciones del propio escritor, Alejandro Dorronsoro en 1882. Sueltos, los cabellos «caen desordenados sobre el pañolón» (cap. 46), tanto como para enredarse en las ramas del rosal del jardín (cap. 45), el rosal del amor fiel. Curiosamente, la escena recuerda la estrofa 21 del Cántico espiritual de San Juan de la Cruz: «De flores y esmeraldas, / en las fres- 
cas mañanas escogidas, / haremos las guirnaldas / en tu amor florecidas / y en un cabello mío entretejidas». En su comentario a esta composición (a pedido de la madre Ana de Jesús, priora de las Descalzas de San José de Granada, en 1584), el santo carmelita pone de relieve el simbolismo de las flores: «virtudes del alma», «llevan la vida y la perfección que la gracia y el amor de Dios les dan; y el del cabello: «es su voluntad de ella [del alma] y amor que tiene al amado». $Y$ añade que el cabello enraizado es el amor ávido, preso fuertemente en las virtudes. La presente lectura avisada propone este encuentro entre prosa romántica colombiana y poesía mística castellana como un rasgo más de la sobresemanticidad sugerente de la obra de Isaacs. Jamás podremos saber - ¿estamos seguros de añadirle algo al alcance semántico en la recepción del personaje si lo probamos a ciencia cierta? - si Isaacs pensó en estos versos del Cántico.

Y así es en muchas ocasiones en las que Efraín reconoce la «fascinación» que en él ejerce la cabellera brillante de María (caps. 45, 31, 32). La última noche que Efraín pasa en la casa de la sierra, dice: «Soñé que María era ya mi esposa: ese castísimo delirio había sido y debía continuar siendo el único deleite de mi alma», a la vez que anota que las trenzas de María halladas entre sus cartas cristalizan tal deleite en su eternidad (cap. 64).

Porque ¿qué halla el lector ingenuo en las páginas del cap. 45 de María?: la esencia simbólica del amor fiel de los jóvenes enamorados, esencia compartible merced a la visión del jardín, símbolo de lo espiritual; a la del rosal, proyección universal del amor perfecto en su unidad divina y humana; la del cabello, fuerza erótica del deseo natural que reúne a un hombre con la mujer que ama.

\subsection{Una variante en el tópico romántico}

María sufre de epilepsia ${ }^{7}$, enfermedad heredada de su madre. A cuenta de dicha enfermedad se podría poner su extremada sensibili-

7 Aquí quizá valga la pena deternernos en este detalle, el de la enfermedad de María, la epilepsia heredada de su madre, Sara. Se habrá de recordar, pues, el carácter simbolico de esta enfermedad, por ejemplo, leyendo a Fray Luis de Granada en su tratado de los Símbolos (II, 32) de 1582, obra que conoció mucha difusión en el XIX. La 
dad, inteligencia del corazón. Con ambas, sensibilidad e inteligencia del corazón, lee, vibrando, e interpreta en su justo valor ese doloroso y magnífico ejemplo de lo que puede la fuerza moral y espiritual de aquel creyente que posea y viva según el genio del cristianismo, al

terrible enfermedad (en griego 'rheuma', es decir, escurrimiento de líquido coral, la epilepsia es desde el XVI un mal de corazón que derriba al que lo sufre), dice Fray Luis, puede manifestarse de manera violenta: espasmos, llantos, ahogos, mordeduras de lengua, espuma que sale por la boca. Tales manifestaciones se consideraban misteriosas y por su carácter mortífero provocaban a la vez respeto y ansiedad. A las convulsiones se las llamaba auras epilépticas o histéricas, y se sabe que uno de los significados del vocablo aura es el de 'hálito', irradiación luminosa de carácter paranormal que se sitúa, por lo general, alrededor de los cuerpos humanos, animales o vegetales, y a su presencia se le atribuye un valor de signo divino de sacralización. Se la llamaba «mal sagrado», o, como en francés, «mal Saint-Jean». Un detalle léxico: un aura es también un ave negra de la familia de los cuervos, de mal agüero, como el bujío de la novela de Isaacs.

En la época del Dr. Jean-Martin Charcot tanto la histeria como la epilepsia eran males eminentemente femeninos. Se consideraba, pues, que la epilepsia predisponía a la fragilidad emocional y afectiva, y quien sufría de ella era alguien que podía refugiarse en la religiosidad, el paroxismo de los sentimientos, el choque circunstancial. Era frecuente que el enfermo, por su sensibilidad ante sucesos traumáticos, desarrollase un mundo fantasmagórico en el que resucitasen viejos comportamientos heredados y que predispusiesen al sufrimiento. A este carácter paranormal alude Efraín en el cap. 11 cuando dice que María lo «magnetiza», con las investigaciones, como referentes, que a finales del siglo XVIII había realizado en La Sallepetrière de París, Franz Mesmer, y ya entrado en siglo XIX, Jean-Martin Charcot en el mismo hospital parisiense.

María está en la edad en que, efectivamente, los ataques epilépticos y un comportamiento exacerbado de sensibilidad se manifiestan, y el alejamiento de Efraín resultará lo suficientemente traumático como para que el mecanismo de la enfermedad se agudice. Efraín lejos, ella irá marchitándose, de ataque en ataque, como el emblemático rosal del jardín de la finca (cap. 62), hasta que «la visita de Dios» llega y ella la acepta «sin haber exhalado una queja». Esta muerte tan serena, de un enfermo convulsivo, sugiere la paz que logra en esos momentos un ser puro de corazón en su condición de elegido de Dios, de predestinado. Es como si la epilepsia estuviera mostrando que el amor de Efraín y de María tampoco es de este mundo.

Isaacs, quien había querido ser médico, ¿habráse detenido a considerar las manifestaciones que caracterizan la epilepsia antes de decidirse a aplicársela a su heroína, prefiriendo esta enfermedad a la tisis, acostumbrada en los personajes femeninos románticos? Ésta es la que causa la muerte de Léa (1832), de Jules Barbey d'Aurevilly; o de La Dame aux camélias (1852), de Alexandre Dumas, hijo; por no citar más que a dos heroínas célebres de la época. Pero, de la tisis se sabía que el desenlace era siempre fatal. en cambio, con la epilepsia se entraba en un ámbito más ambiguo: no se moría forzosamente de este mal. Se podía crear en el lector zozobra, espera angustiosa. En cuanto a la economía del relato, la enfermedad introduce la presencia constante de la muerte. ¿Acaso las apariciones del pájaro negro a lo largo de la historia pueden ligarse simbólica y esencialmente con ella, más allá que el valor de mero presagio funesto? $\mathrm{El}$ matiz tiene su peso, desde el punto de vista del suspense que se crea en el relato. Teniendo en cuenta lo dicho sobre la epilepsia, ¿de qué se muere María, y por qué? ¿De qué mal muere? ¿Muere María de amor, del liebestod romántico? ¿Es María víctima de sus sentimientos: es decir, muere como la Princesse de Clèves (1678) o la Religiosa portuguesa (1669), como el pobre Werther (1776), o el Gonzalo de Córdoba (1801) de Florian?, ise puede calificar la muerte de María de liebestod? María muere de algo que les roba a los suyos, a pesar de ella (no, por ejemplo, como Virginie, quien decide arrojarse al agua para salvar su honor), y que tiene su causa indirecta en el amor frustrado por los familiares. Muere angelicalmente, como un ser fuera del mundo. 
que ilustran las historias de Atala y de René que cuenta Chateaubriand. Sensibilidad e inteligencia de un corazón, enfermo de epilepsia, que se nutre de la práctica de los ejercicios de La Imitación de la Virgen ${ }^{8}$.

De todas maneras, lo que cuenta para el lector en general es esa su naturaleza frágil, enamorada, ideal, perfecta de humanidad esplendorosa. En el capítulo 11 ya da Efraín la medida de tanta perfección que lo «magnetiza»:

Niña cariñosa y risueña, mujer tan pura, y seductora como aquéllas con quienes yo había soñado, así la conocía, pero resignada a mi desdén, era nueva para mi [alude al episodio de las azucenas que Efraín arrojó, pensando que no les estaban dirigidas, cuando había sido María quien se las había puesto en el cuarto]. Divinizada por la resignación, me sentía digno de fijar una mirada sobre su frente.

Naturaleza ideal y perfecta, figura virginal, María es el ejemplo que imitar incluso por su resignación virginal ante los designios de Dios que le dieron esa enfermedad heredada de su madre. María actúa con la misma sumisión con que la Madre del Mesías acoge al ángel Gabriel que le anuncia que será la Madre de Dios hecho hombre (San Lucas, 1, 26-38): «[...] Él será grande. Se Lo llamará hijo del Altísimo; el

Luis Alberto Sánchez (1953: 147) dice que «Esta Elvira no se muere de amor; María se muere de mal del cuerpo: su salud es precaria y se extingue contra su voluntad». La «mala suerte» acompaña a los jóvenes a pesar de los esfuerzos que realiza Efraín, como «buen semita». De todas maneras, María muere marcada por el destino, es una heroína, un paradigma. Su muerte posee un sentido, que es lo que impresiona a los lectores, éstos intuyéndolo más que definiéndolo. Porque, ¿quién podría darle su sentido a la muerte de María?

8 Se reúnen lo paranormal y lo religioso, según el ánimo sintético decimonónico. Respecto de esta Imitación de la Virgen, resumo lo dicho en Marini (1984). Es difícil de saber a ciencia cierta si se trata, por un lado, de la traducción de la que escribió Alexandre-Joseph de Rouville (de 1766): Imitación de la Santísima Virgen María, bajo el modelo de la Imitación de Cristo, de 1838 o de 1847 o de una de las múltiples reediciones del «Tratado quarto» de la Imitación de Nuestra Señora la Soberana Virgen María, que ocupa desde el cap. 6, p. 257, hasta el cap. 56, p. 499 , de la $2 .^{\text {a }}$ parte del Aprovechamiento espiritual del Padre Francisco Arias, impreso en Valencia, en casa de Pedro Patricio Mey, a la plaça de la Yerua, año de 1588. Mc Grady, en nota a su edición de María (Cátedra versión corregida de Labor, 1970) señala que La Imitación de la Virgen es: «Posiblemente un error por La Imitación de Cristo de Thomas a Kempis»); afirma erradamente que la obra de Rouville es un «extracto», es decir, un resumen del libro del Padre Arias. En realidad, Rouville alude a la obra del Padre Arias en el prólogo de su libro para indicar justamente las diferencias entre ambos libros, diferencias relativas particularmente a la forma del desarrollo y de la presentación y no al enfoque del contenido. 
Señor le dará el trono de David, su padre; Él reinará eternamente sobre la casa de Jacob, y su reino no tendrá fin».

Situando ficción y heroína en el horizonte de espera decimonónico colombiano, Arciniegas, 1967: 39) dice: «María es una constante caricia amorosa posada en los paisajes del Cauca». Y añade: «Simbólicamente, Isaacs quiso que María, en su novela, fuera como una imagen lejana, ideal, que viniera a presidir esa liberación», de la que la liberación de los esclavos es emblemática porque, aunque decretada, seguía sin cumplirse enteramente en la práctica. Los lectores que llamo ingenuos intuyen su perfección, la cual, no por ser intuitiva, deja de ser total y verdadera. La profundidad de la naturaleza profunda de María la sitúa en el mundo a la vez que fuera de él.

\section{DEL RECURSO DE LA SOBRESEMANTICIDAD. RETRATO METONÍMICO}

Ha sido necesario poner de relieve la construcción del retrato por sinécdoque del personaje de María para pasar a la elaboración metonímica de éste. La sinécdoque alimenta la lectura ingenua y abre a la recepción sobresemantizada de la heroína. La sinécdoque alimenta la dinámica etiológica que resulta de esta elaboración cruzada en María. Todo se halla preparado como para que la proyección semántica intencional atrape al lector, lo seduzca, y la historia de ficción funcione.

La intención que sobresemantiza se funda en el nombre de la heroína de referente tradicional, fácilmente compartible. Como la Ester bíblica, la estrella o la escondida del Deuteronomio $(31,17)$, la figura de la novela de Isaacs constituye una fuerza que sirve, ama, media y protege a los personajes que la rodean. Como la figura de la Virgen, Puerta del Cielo, es pura, sumisa, dulce y generosa, y también mediadora y profética ${ }^{9}$.

9 Dimensión dada tanto por la carga referencial que conlleva para la época la epilepsia, como por la proclamación del dogma de la Inmaculada Concepción el 8 de diciembre de 1854 en la bula papal Ineffabilis, confirmada por el documento llamado Syllabus, del 8 de diciembre de 1864. Por la Gracia de la Concepción Inmaculada, la Virgen no participa de la maldición que pesa sobre la descendencia de Adán y se acoge a la Redención crística (Génesis, 3, 15; Lucas, 1, 28). El Syllabus poseía también una dimensión política evidente, puesto que condenaba los mismos errores teológicos que la encíclica Quanta Cura, también de 1864; errores inherentes al progreso y al liberalismo modernos: el racionalismo, el socialismo, el comunismo, las 
La sobrina del padre de Efraín, la Ester jamaicana, es hija de su primo Salomón y de Sara, la esposa ya fallecida cuando empieza la historia de María. Con ellos resuenan los versículos de los Proverbios, del Eclesiastés y del Cantar de los Cantares, por un lado; y, por el otro, los nombres de Abrahan, Isaac, Rebeca, Jacob, José, Benjamín, Ester y Efraín, es decir, el origen de las tribus de Israel, pueblo elegido de Dios. Con Salomón, la casa del rey David, la de la Virgen María. Con Sara, la casa de Jacob y la tribu de José, tribu de Efraín, y la ruptura de la Alianza con Dios, puesto que Judá tuvo la idea de que vendieran a José a los ismaelitas, descendientes de Abraham y de la esclava Agar. Y, a la vez, con Sara, la reconciliación con Dios que resulta de la reunión de Judá e Israel, la que se concreta con Salomón y David, hijo de Jessé, de la tribu de Judá, a la que pertenece José, esposo de María, la Virgen.

Si cuatro mujeres bíblicas responden al nombre de Sara ${ }^{10}$, Ester hay una sola: Ester, reina de Persia, aunque hebrea, una extranjera de la tribu de Benjamín, de las casas de Jacob y de José, padre de Efraín. El «astro, estrella», para los persas, y «mirto» purificador, para los judíos, ofrece a los lectores avisados de María su fe, su valor, su religiosidad y patriotismo, rasgos que enriquecen la semántica referencial del personaje central de la novela de Isaacs. Es más, la bíblica Ester fue considerada por los Padres de la Iglesia primitiva y por los Doctores de la Iglesia como una figura hebrea equiparable a lo que será en el catolicismo la Virgen, por lo que nuestra Ester-María es una figura virginal de la tipología judeocristiana. Tantos enlaces del árbol gentilicio de nuestra heroína entre las casas y tribus de Israel, entre el judaísmo y el cristianismo, prueban que la intencionalidad del autor apunta a sugerir transcendencia, profetismo, perfección, paradigma, mesianismo y esperanza en la más pura mentalidad decimonónica universal.

sociedades secretas, las sociedades bíblicas, la civilización moderna desacralizada en general. Estas condenas concernían también al pensamiento del padre Vigil, peruano que defendía hacia 1848 la supremacía de la razón humana respecto del pensamiento divino, ideas que la Santa Sede ya había atacado en 1851 (The Catholic encyclopedia).

La Concepción Inmaculada de María es una convicción defendida desde muy antiguo, que el XIX esgrime como una bandera para contrarrestar al espíritu racional y materialista que resultaba no sólo de las ideas ilustradas sino de los efectos del progreso industrial. De este dogma saca su esencia el concepto que reviste gran importancia en la mentalidad decimonónica, y que preconiza que la Virgen interviene también en la obra mesiánica del Hijo de Dios.

10 Siendo la más concocida la princesa también llamada Jesca, hija de Harán y hermana de Lot, esposa de Abraham. Otra es una nieta de Jacob, llamada también «Tesoro preciado» por su prodigiosa memoria respecto de la liberación de los judíos de Egipto. Además, están la esposa de Tobías, el joven, y una hija de Efraín. 
Una vez llegada a Colombia, Ester será María, católica, bautizada a petición de Salomón (cap. 7), quien decide que su hija llevará ese nombre. El hecho me parece significativo en la medida en que se fija así la ligadura tipológica que asume el personaje con el Antiguo y el Nuevo Testamento, y se le marca un destino privilegiado y significativo de múltiples resonancias semánticas ${ }^{11}$. Resonancias bíblica y evangélica de la heroína de Isaacs, que, proyectadas en la mentalidad decimonónica, sintética, utópica y progresista sugieren la etiología propia de un personaje paradigmático de perfección idílica, heroína del mesianismo femenino postrevolucionario que el XIX sincrético atribuye a las figuras clave de la tradición religiosa universal.

Dice Northrop Frye (1957) que el discurso literario posee diferentes niveles de sentido, todos en relación jerárquica, como fases de análisis y de debate. Éstas serían cuatro: la del sentido literal y descriptivo, la de la forma, la de lo arquetípico y la de lo anagógico. La sobresemanticidad a la que estoy aludiendo, y la que atribuyo al que llamo nivel de lectura avisada, entra de lleno en la fase analítica arquetípica y anagógica, y aún más en ésta última dado el carácter moralizador y religioso que constituye la figura virginal de María en la novela de Isaacs. Fases y caracteres de esencias muy fácilmente compartibles para con el lector ingenuo.

En efecto, pasando del Antiguo Testamento al Nuevo, María establece en sí misma y en un nivel tradicional, la correlación típica de las figuras propias de las exégesis hermenéuticas, figuras de la tipología judeocristiana que se hallan así revestidas de una carga profética. María es, como dice Jean-Noël Guinot (1989), «l'espérance en un avenir». Por ello, la elaboración narratológica de Isaacs, en y para un mundo en crisis, fundada en la figura sobresemantizada de la

11 Ambas ramas genealógicas judeocristianas proponen campos semántico-etimologicos muy ricos para el nombre María. Así, el Dictionnaire de la Bible, de F. Vigouroux, indica que existen 67 etimologías diferentes de él: la del mar, la del maestro, la de la mirra, la de la esperanza, la de lo brillante y la de la iluminación, siendo por este último aspecto María una de las figuras proféticas del Antiguo y Nuevo Testamento (cfr. Tomo IV, $1 .^{\circ}$ parte, 1962).

Es verdad que el árbol genealógico de la Virgen es de difícil determinación, ya que, fehacientemente, sólo se tiene el testimonio de San Pablo, quien afirma que Ella es de la tribu de David. En la Chronica, de la Historia eclesiastica del Venerable Beda, se lee que su padre, Joaquín, desciende de Barfantar y éste, de Pantar, quien, por Leví y Natán, desciende de David. En cuanto a Ana, su madre, nacida en Belén, pertenece a la tribu de Judá, según la Historia de la Natividad de la Virgen, texto atribuido a San Jerónimo, pero considerado apócrifo. Sin embargo, inspiró a Jacopo da Voragine para su Leyenda áurea, libro que desde el siglo XIII conoce un éxito que no se desmiente en el siglo XIX y que cimentó la vida legendaria de la Virgen. 
heroína, halló el eco que sabemos que tuvo, ha tenido y sigue teniendo María.

María es, a la vez, una figura que reúne dos tradiciones bíblicas, las de Ester y la de María. Dos momentos de la historia monoteísta universal que la convierten en una figura del mesianismo que anuncia el Antiguo Testamento y se cumple en el Nuevo. Al igual que Ester y María, la heroína de Isaacs es un ejemplo moral y esperanzador para el mundo decimonónico que, tanto en Europa como en América, busca ordenar y equilibrar lo que perdió su aparente equilibrio: Francia, buscando cómo colmar el vacío que dejó la pérdida de espiritualidad cristiana; América, buscando cómo dominar los entusiasmos antagónicos que la estironean desde sus extremos políticos, sociales, económicos y, por qué no, religiosos.

Y, aunque Isaacs presenta una familia, un mundo, una región en perfecta armonía, cuando en Colombia las circunstancias se hallaban lejos de dicha situación ideal, los lectores ingenuos de entonces comprendieron con el corazón la historia de Efraín y de María. Fue como si la tarea creativa de Isaacs se hallara puesta en el abismo de la carne de su heroína, proponiendo indirectamente la imagen de una sociedad armónica deseada, ansiada. Como dice Eduardo Mallea: «Un escritor refleja de su tiempo lo que su tiempo no encuentra», y añade: «[...] pero lo que un genio tiene de eterno es su permanente actualidad».

\section{Referencias bibliográficas}

AA.VV. (1912). The Catholic Encyclopedia. N. York: Robert Appleton, vol. 14.

ARCINIÉGAS, G. (1967). Genio y figura de Jorge Isaacs. Buenos Aires: Eudeba.

BARTHES, R. (1967). «Proust et les roms». En To honor Roman Jakobson Essays on the Ocasion of his Seventieth Birthday 11 October 1996, 150158. La Haya-París: Moreton \& Co. New York: Editors Publishers.

DulaEY, M. (1989). «Joseph le patriarche, figure du Christ». Figures de L'Ancien Testament, 83-105.

FRYE. N. (1957). Anatomy of Criticism.

GuinOT, J.N. (1989). «La Typologie comme technique ferménentique». Figures de l'Ancien Testament, 1-34.

LEwIN, B. (1987). Los criptojudios. Un fenómeno religioso y social. Buenos Aires: Milá. 
Marini Palmieri, E. (1984). «Commentaires á propos de María, de Jorge Isaacs». En Le roman romantique latino-américaine et ses prolongements, AA.VV., 143-148. París: L'Harmatan.

MARTIN, W. (1986). Recent Theories of Narrative. Ithaca y Londres: Cornell University Press.

MONTEVERDE. F. (1944). «Jorge Isaacs, judío de América». Judaica (octubre-diciembre), 188-193.

SÁNCHEZ, L.A. (1953). Proceso y contenido de la novela hispanoamericana. VV.AA. (1912). The Catholic Encyclopedia. New York: Robert Appleton, vol. 14.

VICH-CAMPOS, M. (1984). «La toilette d'Ephraim, un motif d'exotisme?» En Le roman romantique latino-américain et ses prolongements, AA.VV., 149-158. París: L'Harmattan. 